\title{
PROPAEDEUTIC STUDENTS OF EDUCATIONAL PROGRAMS FOR THE IMPLEMENTATION OF THE SUBJECT-subjective RELATIONS IN TECHNOLOGICAL EDUCATION IN PRIMARY SCHOOL
}

\author{
A. Kalinova* \\ Faculty of Education, Trakia University, Stara Zagora, Bulgaria
}

\begin{abstract}
:
In order to know the specifics of a subject-subject relationship, students of pedagogical specialties are included in non-traditional training course "Theory and methods of technological education in elementary school."

The publication presenting options propedeutics students of pedagogical specialties for carrying out subject-subjective relations in technological education in primary school. Through a survey of students establish their views on the effectiveness of the training.
\end{abstract}

Key words: propaedeutic, subject-subject relationship, technological education, students

\section{INTRODUCCTION}

The training of students of pedagogical specialties included line disciplines, through which carried out their professional training. As the students are in the process of training and have gained teaching experience in their future work they initially rely solely on their knowledge of theory - innovations in teaching approaches, methods, new solutions, etc. One of the main priorities of academic training students to develop the ability to think. This is because in its future work, each student must take individual decisions on the basis of their competence. It is known that one can teach others something only if he previously trained on it.

In many subjects the students show knowledge of reproductive level as forms of traditional training. Naturally, this can be reflected in their future profession.

The ultimate goal of any training and education is to achieve the so-called. developmental training - training which will develop the personality of the little child or student. Similar is the training of students of pedagogical specialties not be reproductive learning and creativity, training in thinking, decision making, team interaction. This is the reason to conduct research among students of

\footnotetext{
${ }^{*}$ Correspondence to: Angelina Kalinova, Trakia University, Faculty of Education, Bulgaria, angy_80@abv.bg
}

pedagogical specialties, which are included in non-traditional form of training in the course "Theory and methods of technological education in elementary school."

\section{METHODOLOGY OF THE RESEARSH:}

The object is the training of students of pedagogical specialties in the discipline "Theory and methods of technological education in elementary school."

The subject of study is propaedeutic students to carry out a subject-subjective relations in technological education in primary school.

The aim of the study was to determine the efficiency of the propedeutics with students to implement the subject-subjective relations in technological education in primary school.

The study involved 60 students from the Bachelor degree course Preschool and Primary School Education. It periodically assigns task to develop plan syllabus a lesson in life and home appliances in elementary school. Assigned to them beforehand requirements are: - The existence of a contingent (composition) students in class (similar to actual practice - students with different cognitive and practical possibilities with different ethnic backgrounds, different parental support, with special educational needs, etc.); - $\quad$ Availability of goal setting consistent with the curriculum; 
Availability of operational objectives (transformation of regulated targets achievable goals in this situation);

Compliance with the operational objectives of the opportunities of students from the class (Contingent (composition));

- Provided conditions for independent choice of activity of students (subjectsubjective interaction);

- $\quad$ Provided conditions for the expression of creativity;

- $\quad$ Provided conditions for safe operation;

- $\quad$ Implemented integrative connections.

Realization of subject-subjective interaction in academic training in the theory and methodology of technological training of students implies the use of most elements of personality-oriented approach. One of these elements is self-assessment. It is performed in a peculiar way. Students are asked to selfassessment task their projects and mutual them reviewed. Peer review is a result of the interaction of the students in pairs with one project reviewed the other, guided by the set requirements and objective criteria. The teacher also receives a grade, but not the project of students and their review for it. If it is not fair and it does not reflect all the benefits and shortcomings of the project, both projects are not accepted. Respondents included in this type of interaction with them in order to form the ability to work in a team, striving for cooperation, exchange of ideas, ie they put themselves in the position of subjects in his academic training. Thus is formed in them a sense of responsibility towards others.

Upon completion of academic training, students take part in the survey, which aims to establish:

- What are their attitudes to new pedagogical ideas and solutions (Question - 7, $15)$;

- $\quad$ The extent to recognize the importance of implementing a subject-subject interaction in technological training of young students (Question - 16);

What academic training has contributed to their future professional realization (question 12);

We analyze the results of the study based on the following criteria:

- Awareness of students about developments in pedagogical theory;

- Personal position of the students on the issue of implementation of subjectsubjective interaction in teaching;

- Academic competence for technological training;
Sensitivity (susceptibility) to new pedagogical ideas and solutions.

\section{RESULTS}

With respect to the first criterion "Awareness of students about developments in pedagogical theory" and all respondents participated in training students $(100 \%)$ reported that there was no ambiguity regarding the design and development of the course project. They were previously familiar with the theoretical and methodological foundations of the discipline, with current theories, concepts, principles, methods and approaches for technology education in primary school. Future educators believe that this form of academic training was very useful for them, since they themselves have felt as subjects in training. All students are of the opinion that the importance of subject-subjective relations is paramount.

From the results it can be concluded that all respondents future teachers to be fully informed of developments in pedagogical theory due to academic training in the theory and methodology of technology training.

The results of a second criterion "Personal position of the students on the issue of implementation of subject-subjective interaction in education" are very interesting. They show the extent to which students recognize the importance of subject-subjective relations training. Their task is to evaluate the project of a colleague on a number of criteria, among which two are:

- $\quad$ Provided conditions for independent choice of activity;

- Provided conditions for the manifestation of creativity.

By participating in the survey they express their personal views on the issue of implementation of subject-subjective interaction by defining the importance of these criteria. As a matter of № 16. questionnaire "You self-assessment projects on a number of criteria, among which are two: Provided conditions for independent choice of activity and provided conditions for the expression of creativity. What is the significance of these criteria? "Is an open response, we present the most common recurring answer, namely:

"I had a choice of everything and could not declare. That makes me a subject in training. I had a choice of textbook, topic, partner, Contingent (composition) of the students, a way of developing the project, a way to fix it ... ";

- "By these criteria manifests the creativity of the student."; 
KALINOVA A.

"Give freedom of expression.";

"Show the right to personal position, which leads to development in the learning process." "Work on these criteria allow the implementation of the subject - subjective interaction.";

"Provide us opportunities to take creative criteria are important for our overall development not only as teachers but also as individuals."

"Everyone has the choice of activity and creative, which will be useful in practice.";

"Self solve tasks without imposing stereotypes."

"The student depends on yourself. If not active - lost if active - wins. If the student does not take advantage of the conditions for the manifestation of creativity like nothing doing. "" These criteria put me in the position of the entity makes its own decisions about how to work.";

"By these criteria, I had the opportunity to manifest their individual abilities.".

Regarding the second criterion can draw the following conclusions: students surveyed understand the importance of the set criteria for developing a plan outlining a lesson. Compliance providing conditions for implementation of subject-subjective interaction. Future teachers understand that student could be put in the position of the subject, by offering a choice of activity in teaching Home and equipment. Students say that they themselves have freedom of expression, have shown creativity, they had a choice and the right to express their personal opinion.

From the foregoing, we conclude that students who participated in such training, favor the ability to express personal views and consider that it is an essential element of the problem for the realization of subject-subjective interaction. The reason for this is their participation as subjects in academic training. "What I hear, I forget. What he saw - he will remember. What do - will understand. "(Confucius).

Examined whether students have the necessary "Academic competence for technological training" establish the analysis of the results obtained in third criterion.

Respondents' answers often overlap and this is a reason to introduce them summarized. By the summary illustrate the synthesis of the acquired content of training, technology implementation training to subject-subject- based and constructed personalities qualities. Some of the answers of students surveyed:

- "Hone their skills for team interaction."

- $\quad$ "I can create conditions for learning teamwork."

- $\quad$ "The project gives an opportunity for personal expression."

"I received useful knowledge for the implementation of modern education."

- $\quad$ "I gained confidence." "I got to thinking outside the box."

- $\quad$ "I got a better preparation." "I learned to find my mistakes."

- $\quad$ "I had a choice and became more independent."

- $\quad$ "Contribute to the development of my will."

- $\quad$ "I understand the essence of the learning process in life and home appliances .;

- $\quad$ "He taught me that cooperation is the foundation of success"

The results obtained by this criterion can be concluded that future teachers have learned what you need to learn and pupils in primary school - cooperation, self-confidence, independence.

This allows us to conclude that students have acquired the competence not only of the methodology of traditional technological training, but they met with new methods and approaches through which carried out personoriented training, subject-subjective interaction.

Received above results largely show what level of "sensitivity (susceptibility) to new pedagogical ideas and solutions." The surveyed students said that the form of training on this course very different. As an argument for showing sensitivity to new and different analyze the recommendations, students are asked to head to the teacher. These recommendations are different, but all are in the context of a sense of satisfaction expressed by the different presentation of information to support guidance and cooperation they have received, about the opportunity for personal expression, to provide conditions in which each student has demonstrated creativity to form lateral thinking. Future teachers say that their academic training is attached personoriented approach - each were assisted carried interaction through teamwork, leading to cooperation and determines the student's individual success - where necessary, his assists, missing information is supplemented in terms of team interaction. 


\section{CONCLUSION}

According to the results of the survey of students of "Preschool and Primary School Education" can be concluded that they are familiar with current theories, concepts, methods, and approaches for technology education in primary school. Their attitudes about new pedagogical ideas and solutions are positive. Their readiness for the implementation of new pedagogical technology in teaching home life and equipment in elementary school there.

\section{REFERENCES}

1. Andreev, M. (2001) Learning process. Didactics. Sofia.
2. Vasilev, D. (1992) Pedagogy. University edition. Sofia

3. Vasileva E. (2002) Child in elementary school. Sofia

4. Ivanov, G., E. Vasileva (2012) Fundamentals of Primary School Education. Stara Zagora.

5. Ivanov, G. (2008) Pedagogical interaction in technological preparation of children from 3 to 11 years. Stara Zagora.

6. Ivanov, G. (2008) Employment skills of small pupil. Stara Zagora.

7. Ivanov, G. (2008) Multi-sensing in technical and technological training. Stara Zagora.

8. Maslow, E. (2002). Motivation and personality. Publishing House Prosveta. Sofia. 